\title{
Configurações
}

configurações

Revista Ciências Sociais

$18 \mid 2016$

Ciganos e Educação

\section{Introdução-Ciganos e Educação}

\section{Olga Magano, Maria Manuela Mendes e Sílvia Gomes}

\section{(2) OpenEdition \\ Journals}

Edição electrónica

URL: http://journals.openedition.org/configuracoes/3514

DOI: 10.4000/configuracoes.3514

ISSN: 2182-7419

\section{Editora}

Centro de Investigação em Ciências Sociais

\section{Edição impressa}

Paginação: 5-7

ISSN: 1646-5075

\section{Refêrencia eletrónica}

Olga Magano, Maria Manuela Mendes e Sílvia Gomes, «Introdução-Ciganos e Educação », Configurações [Online], 18 | 2016, posto online no dia 30 dezembro 2016, consultado o 10 dezembro 2020. URL : http://journals.openedition.org/configuracoes/3514 ; DOI : https://doi.org/10.4000/ configuracoes.3514 


\title{
Introdução Ciganos e Educação
}

\author{
OLGA MAGANO* \\ Universidade Aberta \\ MARIA MANUELA MENDES** \\ Universidade de Lisboa \\ SÍLVIA GOMES*** \\ Universidade do Minho
}

Em Portugal e na Europa em geral continua a verificar-se uma grande desigualdade persistente no que se refere ao acesso à escolaridade e ao sucesso no percurso educativo por parte de indivíduos e famílias ciganas. A educação formal é importante para os direitos sociais e culturais dos indivíduos e uma das principais chaves para a entrada no mercado formal de emprego e para a garantia das condições básicas de sobrevivência. No entanto, entre as pessoas ciganas continuam a verificar-se as mais altas taxas de analfabetismo, abandono escolar precoce - antes de terminar o $1^{\circ}$ ciclo de estudos - não obstante o esforço de algumas políticas sociais educativas, nomeadamente a escolaridade obrigatória. São ainda residuais os casos de pessoas ciganas que concluem estudos ao nível do $3^{\circ}$ ciclo de escolaridade e ainda mais raros os casos de pessoas que prosseguem os estudos ao nível do Ensino Secundário e Ensino Superior.

Este dossier da Revista Configurações intitulado Ciganos e Educação, que agora se dá à estampa, procura equacionar esta realidade social sob o ponto de vista multidisciplinar e transversal de partilha de saberes e práticas

\footnotetext{
**Docente na Universidade Aberta, Departamento de Ciências Sociais e de Gestão e Investigadora do Instituto Universitário de Lisboa (ISCTE-IUL), CIES-IUL, Lisboa e do CEMRI-UAb. E-mail: olga. magano@uab.pt

** Docente na Faculdade de Arquitetura da Universidade de Lisboa, Investigadora no Instituto Universitário de Lisboa (ISCTE-IUL), CIES-IUL. Email: mamendesster@gmail.com

**** Doutorada, investigadora de pós-doutoramento no Centro Interdisciplinar de Ciências Sociais, polo Universidade do Minho (CICS.NOVA - polo UM), e Investigadora na Unidade de Investigação em Criminologia e Ciências do Comportamento (UICCC.ISMAI). Email: silvia.gomes@ics.uminho.pt.
} 
no campo da investigação sociológica em particular e das Ciências Sociais em geral. Neste sentido, reúne um conjunto de textos com objetos, paradigmas de análise e metodologias díspares, mas que contribuem certamente para ampliar o nosso conhecimento sobre as articulações famílias, indivíduos, escola e políticas públicas.

Destaca-se um conjunto de textos que têm como mote o sucesso e/ou insucesso educativo. A abrir, surge o texto da autoria de Olga Magano e Maria Manuela Mendes, que tem por base uma investigação qualitativa realizada nas áreas metropolitanas de Lisboa e Porto, desvelando os fatores que dificultam ou favorecem a escolarização de pessoas ciganas. De realçar que a continuidade das trajetórias depende em grande medida de políticas e programas públicos, mas também com outros fatores explicativos inerentes ao indivíduo, ao tipo de apoio do seu grupo familiar, à presença de figuras de referência, à importância dos pares e fatores institucionais ínsitos ao funcionamento da escola pública.

Numa perspetiva de complementaridade, situa-se o texto de Maria da Conceição Tomé, Anabela Carvalho, José Sousa, Dinis Saraiva, António Domingues e Maria Fernanda Oliveira, que analisa em particular o sucesso dos alunos de origem cigana numa escola da cidade de Viseu, retratando uma experiência que visa despertar os estudantes para situações de racismo referidas em livros, proporcionando-se ainda aos docentes o acesso a formação sobre cultura cigana e diversidades culturais, de um modo geral.

A escolarização, insucesso e abandono escolar por parte das crianças ciganas no nordeste transmontano, sobretudo em meio rural, são fenómenos analisados por Lurdes Nicolau. Para além disso, a autora auscultou pais e professores, o que permite aclarar as principais dificuldades destas crianças na escola, mencionando vários fatores que contribuem para o abandono e insucesso escolar das mesmas.

Pedro Abrantes, Teresa Seabra, Tiago Caeiro, Sofia Almeida, Raquel Costa apresentam um estudo realizado numa escola de Lisboa em que há uma enorme concentração de alunos ciganos e que agrupa estudantes de origem cigana na mesma escola, num exemplo flagrante de discriminação e racismo.

Tendo por base dados do Estudo Nacional sobre as Comunidades Ciganas em Portugal, Pedro Candeias revela que apesar da grande maioria das pessoas inquiridas ter baixos níveis de escolaridade, há uma diversidade de situações, em que alguns se destacam por terem prolongado mais o percurso escolar. $\mathrm{O}$ autor explicita as características que diferenciam os ciganos portugueses com escolaridade ao nível secundário ou superior dos restantes menos escolarizados, assim como, esclarece o leitor quanto aos impactos da escolarização em várias dimensões da vida dos inquiridos.

Fazendo uma análise diacrónica e sincrónica sobre um mesmo bairro da cidade de Lisboa em 2003 e 2015, Daniel Seabra Lopes e Ana Rita Costa mobilizam um olhar comparativo e etnográfico, evidenciando a partir dos resultados 
obtidos em cada momento o que se alterou e o que se manteve. Ao compararem os dados relativos à educação e ao emprego em períodos diferentes, verificam uma situação de imobilismo e de estagnação, refletindo sobre as razões subjacentes a tal situação.

A fechar este dossier, Ana Sofia Neves, Ariana Correia e Paula Allen refletem sobre um projeto de intervenção e o seu impacto junto das mulheres que participaram nesse estudo através da frequência de um conjunto de ações de formação e de iniciativas de empoderamento.

Apesar da diversidade dos textos agora disponíveis, uns de carácter mais lato e outros de carácter mais micro, estamos seguras de que contribuem com novos olhares sobre as pessoas ciganas em Portugal, tendo como foco central as questões em torno da educação. Esperemos que a diversidade e atualidade dos temas abordados suscitem a leitura deste dossier. 